\title{
Homocysteine, folate, methylation, and monoamine metabolism in depression
}

Teodoro Bottiglieri, Malcolm Laundy, Richard Crellin, Brian K Toone, Michael W P Carney, Edward H Reynolds

\begin{abstract}
Objectives-Previous studies suggest that folate deficiency may occur in up to one third of patients with severe depression, and that treatment with the vitamin may enhance recovery of the mental state. There are, however, difficulties in interpreting serum and red cell folate assays in some patients, and it has been suggested that total plasma homocysteine is a more sensitive measure of functional folate (and vitamin B12) deficiency. Other studies suggest a link between folate deficiency and impaired metabolism of serotonin, dopamine, and noradrenaline (norepinephrine), which have been implicated in mood disorders. A study of homocysteine, folate, and monoamine metabolism has, therefore, been undertaken in patients with severe depression.
\end{abstract}

Methods-In 46 inpatients with severe DSM III depression, blood counts, serum and red cell folate, serum vitamin B12, total plasma homocysteine, and, in 28 patients, CSF folate, S-adenosylmethionine, and the monoamine neurotransmitter metabolites 5HIAA, HVA, and MHPG were examined. Two control groups comprised 18 healthy volunteers and 20 patients with neurological disorders, the second group undergoing CSF examination for diagnostic purposes.

Results-Twenty four depressed patients $(52 \%)$ had raised total plasma homocysteine. Depressed patients with raised total plasma homocysteine had significant lowering of serum, red cell, and CSF folate, CSF S-adenosylmethionine and all three CSF monoamine metabolites. Total plasma homocysteine was significantly negatively correlated with red cell folate in depressed patients, but not controls. Conclusions-Utilising total plasma homocysteine as a sensitive measure of functional folate deficiency, a biological subgroup of depression with folate deficiency, impaired methylation, and monoamine neurotransmitter metabolism has been identified. Detection of this subgroup, which will not be achieved by routine blood counts, is important in view of the potential benefit of vitamin replacement.

(F Neurol Neurosurg Psychiatry 2000;69:228-232)

Keywords: homocysteine; folate; monoamines; depression
Over the past 25 years several surveys have shown a high incidence of folate deficiency in psychiatric populations, especially in those with depression. ${ }^{1}$ Most early studies relied on serum folate determinations but more recent studies utilised red blood cell folate assays, which are more indicative of intracellular stores, and have confirmed that up to one third of patients with severe depression have folate deficiency. ${ }^{2}{ }^{3}$ Although folate deficiency is often the result of depression due to poor diet, there is evidence from controlled studies ${ }^{134}$ that whether the deficiency is secondary or primary, folate replacement will enhance recovery of the mental state, probably by a mechanism linking methylation in the nervous system to mood. ${ }^{5}$

A diagnosis of folate deficiency may be uncertain when relying on a serum folate determination alone. For example, serum folate may be decreased after acute dietary restriction of the vitamin although intracellular folate stores may be normal. Conversely, serum folate may rapidly increase after high intake of folate from a recent meal while intracellular stores may be low. Furthermore, there is also some uncertainty as to the concentration of red cell folate that defines a true deficiency state. There is evidence that even a so called borderline deficiency may adversely affect the mental state. ${ }^{3}$ On the other hand, a minority of patients with megaloblastic anaemia due to folate deficiency (or vitamin B12 deficiency) do not exhibit any neuropsychiatric complications, at least in the short term. ${ }^{6}$

Recently several studies have shown that total plasma homocysteine is a sensitive marker of functional deficiency of either folic acid or vitamin B12. The synthesis of methionine from homocysteine requires a supply of methyl groups from methyl folate, and also vitamin B12 as a cofactor. Thus functional deficiency of either vitamin results in raised concentrations of homocysteine. ${ }^{78}$ Methionine is the immediate precursor of S-adenosylmethionine (SAM), the methyl donor in innumerable methylation reactions in the brain. ${ }^{15}$

Biological research in depression currently involves many aspects of neurotransmitter, hormone, and vitamin metabolism, reinforced by functional imaging studies, but for at least 40 years a major area of interest has been in the field of monoamine neurotransmitter metabolism, especially serotonin (5HT), dopamine (DA), and noradrenaline (NA). ${ }^{9}$ It is, therefore, of particular interest that there is clinical and experimental evidence linking folate, SAM, and monoamine metabolism, probably through the biopterin pathway. ${ }^{510}$ We have, 
Table 1 Demographic data of patient groups

\begin{tabular}{llll}
\hline Group & $n$ & $\begin{array}{c}\text { Malel } \\
\text { female }\end{array}$ & $\begin{array}{l}\text { Age } \\
\text { (mean SD) (y) }\end{array}$ \\
\hline Normal controls & 18 & $9 / 9$ & $34(10)$ \\
Neurological controls: & 3 & & \\
$\quad$ Peripheral neuropathy & 2 & & \\
$\quad$ Motor neuron disease & 4 & & \\
Sciatica & 2 & & \\
Spinal stenosis & 2 & & \\
Back pain & 1 & & \\
Disc prolapse & 1 & & \\
Headache & 1 & & \\
$\quad$ Mechanical nerve root damage & 3 & & \\
Sleep disorder & 1 & & \\
Vertebrobasilar ischaemia & 20 & $9 / 11$ & $53(15)$ \\
Total & & & \\
Depression & 46 & $19 / 27$ & $53(16)$ \\
\hline
\end{tabular}

therefore, undertaken a study of the relation between folate, SAM, and monoamine metabolism, including total plasma homocysteine as a sensitive marker of folate status, in a group of severely depressed patients.

\section{Patients and methods}

Forty six inpatients in the Departments of Psychiatry, Northwick Park Hospital and Psychological Medicine, King's College Hospital, with a DSM-III diagnosis of depression and a Hamilton score greater than 17 were studied between 1989 and 1994. Patients with evidence of cognitive impairment, severe physical illness, or drug or alcohol misuse were excluded. All previous psychotropic medication had been withdrawn for at least 1 week before sampling.

Two control groups consisted of 18 normal healthy volunteers and 20 patients with various neurological disorders. The age and sex of the patients and two control groups and the diagnosis in the neurological controls are summarised in table 1 .

After informed patient consent, $5 \mathrm{ml} \mathrm{CSF}$ was examined for folate, SAM, and the monoamine metabolites 5-hydroxyindole acetic acid (5HIAA), homovanillic acid (HVA), and 3-methoxy-4-hydroxyphenyl glycol (MHPG) in 28 of the depressed patients and 17 of the neurological control patients. Samples of CSF were obtained between 900 and 1100 am with the patients in the recumbent position, after overnight fasting. Fasting blood samples were obtained in all patients (at the same time as the CSF sample in those undergoing lumbar puncture) for examination of full blood count (Coulter S counter), serum and red blood cell folate, serum vitamin B12, and total plasma homocysteine.

Whole blood was prepared for red cell and serum folate, serum vitamin B12, and total plasma homocysteine. CSF was prepared for folate analysis by the addition of $900 \mu 1 \%$ ascorbic acid (pH 7.0) to $100 \mu$ l CSF. CSF was prepared for SAM analysis by the addition of 1 $\mathrm{ml}$ perchloric acid $(0.6 \mathrm{M})$ to $2 \mathrm{ml} \mathrm{CSF}$. All samples were stored at $-20^{\circ} \mathrm{C}$ until the time of analysis. Red cell, serum, and CSF folate were determined by microbiological assay using Lactobacillus casei. ${ }^{11}$ Serum vitamin B12 was determined by an isotope dilution assay using polyacrylamide bound intrinsic factor to bind ${ }^{57} \mathrm{Co}-$ cyanocobalamin and endogenous vitamin B12. ${ }^{12}$ Total plasma homocysteine was determined by high performance liquid chromatography (HPLC) coupled to a fluorescence detector. ${ }^{13}$ CSF SAM was determined in perchloric acid extracts by a double labelled enzymatic assay. ${ }^{14}$ CSF 5-HIAA, HVA, and MHPG were determined by HPLC coupled to amperometric detection. ${ }^{15}$

The study was approved by the ethics committees of Northwick Park and King's College Hospitals.

\section{STATISTICAL ANALYSIS}

Statistical significance between groups was assessed using the pooled estimate of the SD obtained by analysis of variance (ANOVA) of $\log$ transformed data. The $t$ values were adjusted for multiple comparisons using Dunnett's test. Correlations were performed using Pearson's correlation coefficient.

\section{Results}

None of the controls or patients were anaemic or macrocytic. The MCV range in the normal controls was 79-98 (mean (SE) 91 (4)) $\mathrm{fl}$, in neurological controls it was 83-97 (91 (5)), fl and in depressed patients 80-97 (89 (4)) fl.

TOTAL PLASMA HOMOCYSTEINE

The mean total plasma homocysteine value was significantly increased in the depressed group compared with the normal $(t=4.07$, $\mathrm{p}<0.01)$ or neurological $(t=5.02, \mathrm{p}<0.001)$ control groups (fig 1, table 2). Twenty four of 46 depressed patients (52.1\%) had a total plasma homocysteine concentration above the normal and neurological control range (3.4$11.9 \mu \mathrm{mol} / 1$, fig 1). Depressed patients were

Table 2 Homocysteine, vitamin B12, folate, SAM, and monomine metabolites in depression

\begin{tabular}{|c|c|c|c|c|c|c|c|c|c|}
\hline & $\begin{array}{l}\text { Total plasma } \\
\text { Hcy }(\mu m o l / 1)\end{array}$ & $\begin{array}{l}\text { Serum vitamin } \\
\text { B12 (ng/1) }\end{array}$ & $\begin{array}{l}\text { Serum folate } \\
(\mu g / 1)\end{array}$ & $\begin{array}{l}R B C \text { folate } \\
(\mu g / 1)\end{array}$ & $\begin{array}{l}\text { CSF folate } \\
(\mu g / 1)\end{array}$ & $\begin{array}{l}\text { CSF SAM } \\
\text { (nmol/1) }\end{array}$ & $\begin{array}{l}\text { CSF 5-HIAA } \\
\text { (nmol/1) }\end{array}$ & $\begin{array}{l}\text { CSF HVA } \\
(\text { nmol/1) }\end{array}$ & $\begin{array}{l}\text { CSF MHPG } \\
\text { (nmol/1) }\end{array}$ \\
\hline Normal controls $(n=18)$ & $7.6(2.4)$ & $344(105)$ & $7.0(3.0)$ & $362(175)$ & - & - & - & - & - \\
\hline Neurological controls $(n=20)$ & $6.6(2.0)$ & $410(154)$ & $9.1(3.9)$ & $373(97)$ & $\begin{array}{l}22.3(3.8) \\
(\mathrm{n}=17)\end{array}$ & $\begin{array}{l}163(30) \\
(n=16)\end{array}$ & $107(23)$ & $233(49)$ & $56.3(18.5)$ \\
\hline $\begin{array}{l}\text { Depression: } \\
\text { All patients } \quad(n=46)\end{array}$ & $13.2(6.2)^{\mathrm{b}, \mathrm{c}}$ & $361(148)$ & $5.9(4.0)$ & $247(126)^{\mathrm{b}, \mathrm{d}}$ & $\begin{array}{l}19.4(7.6) \\
(\mathrm{n}=28)\end{array}$ & $\begin{array}{l}146(36) \\
(\mathrm{n}=28)\end{array}$ & $\begin{array}{l}95(42) \\
(\mathrm{n}=28)\end{array}$ & $\begin{array}{l}211(108) \\
(\mathrm{n}=28)\end{array}$ & $\begin{array}{l}46.2(14.0) \\
(\mathrm{n}=28)\end{array}$ \\
\hline Normal Hcy group $\quad(n=22)$ & $8.2(1.9)$ & $392(133)$ & $7.2(4.0)$ & $320(118)$ & $\begin{array}{l}21.8(6.2) \\
(\mathrm{n}=15)\end{array}$ & $\begin{array}{l}160(35) \\
(n=15)\end{array}$ & $\begin{array}{l}104(48) \\
(\mathrm{n}=15)\end{array}$ & $\begin{array}{l}251(124) \\
(\mathrm{n}=15)\end{array}$ & $48.6(16.1)$ \\
\hline High hcy group $\quad(n=24)$ & $17.7(5.4)^{\mathrm{a}, \mathrm{c}}$ & $334(157)$ & $4.6(3.7)^{\mathrm{d}}$ & $179(92)^{\mathrm{b}, \mathrm{c}}$ & $\begin{array}{l}16.6(8.4)^{e} \\
(\mathrm{n}=13)\end{array}$ & $\begin{array}{l}129(29)^{d} \\
(n=13)\end{array}$ & $\begin{array}{l}85(31)^{\mathrm{g}} \\
(\mathrm{n}=13)\end{array}$ & $\begin{array}{l}165(62)^{e} \\
(n=13)\end{array}$ & $\begin{array}{l}43.5\left(11.2^{) \mathrm{f}}\right. \\
(\mathrm{n}=13)\end{array}$ \\
\hline
\end{tabular}

Values are mean (SD). Hcy=homocysteine. Versus normal controls: $a=p<0.001 ; b=p<0.01$. Versus neurological controls: $c=p<0.001 ; d=p<0.01 ; e=p<0.02$; $\mathrm{f}=\mathrm{p}<0.04 ; \mathrm{g}=\mathrm{p}<0.05$. 


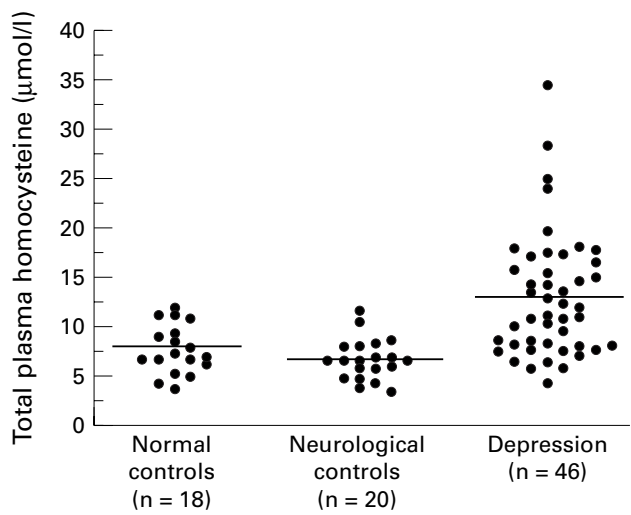

Figure 1 Total plasma homocysteine in normal controls, neurological controls, and depression group.

subdivided into: (1) normal homocysteine group (plasma concentration $<11.9 \mu \mathrm{mol} / \mathrm{l}$ ), or (2) high homocysteine group (plasma concentration $>12.0 \mu \mathrm{mol} / 1$ ). Blood and CSF metabolites were, therefore, examined in the depressed group as a whole as well as in these two subgroups.

Total plasma homocysteine concentrations were not significantly related to age, weight, previous psychotropic medication, or to duration of depression. However, mean (SE) Hamilton scores in the high homocysteine group (26.30 (1.02)) were significantly higher than in the normal homocysteine group (23.00 (0.72)) $(t=2.4, \mathrm{p}<0.01)$.

RED CELL AND SERUM FOLATE

Of the 46 depressed patients, 14 (30.4\%) had red cell folate values below the normal range $(<150 \mu \mathrm{g} / \mathrm{l})$. The mean red cell folate in the depressed group was significantly lower than the normal $(t=3.12, \mathrm{p}<0.01)$ and neurological $(t=3.57, \mathrm{p}<0.01)$ control groups, and even more so in the depressed subgroup with high plasma homocysteine compared to the normal $(t=4.73, \mathrm{p}<0.01)$ and neurological $(t=5.18$, $\mathrm{p}<0.001$ ) control groups (table 2 ). In the whole depressed group, excluding four patients with low serum vitamin B12, total plasma homocysteine was significantly correlated with red cell folate $(r=-0.50, \mathrm{n}=42 ; \mathrm{p}<0.01$; fig 2$)$. There were no significant correlations between total plasma homocysteine and red cell folate in either the normal or neurological control groups.

The fall in serum folate in the depressed group as a whole was not significant, but in the subgroup with high homocysteine serum folate was significantly lower than in the neurological control group ( $t=3.94, \mathrm{p}<0.01$, table 2 ). Red cell and serum folate concentrations were unrelated to age or to Hamilton scores.

\section{SERUM VITAMIN B12}

The mean serum vitamin B12 concentration was not significantly different in any of the groups of depressed patients when compared with the normal and neurological control groups. Four depressed patients had subnormal serum vitamin $\mathrm{B} 12$ values $(<160 \mathrm{pg} / \mathrm{ml})$, three of whom had elevated homocysteine concentrations. There were no significant

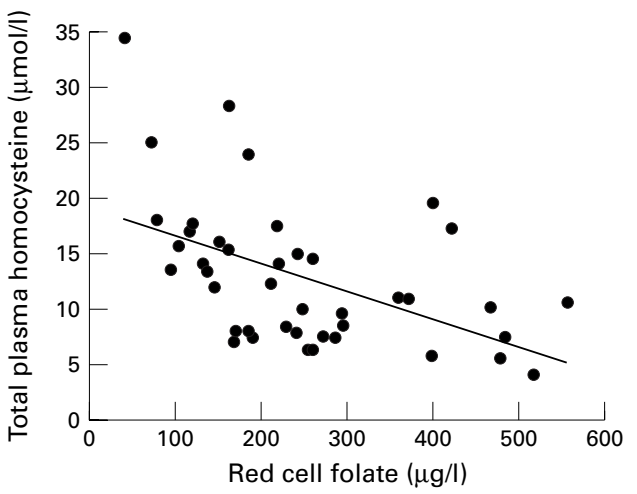

Figure 2 Relation between total plasma homocysteine and red cell folate in depression.

correlations between serum vitamin $\mathrm{B} 12$ and total plasma homocysteine in any of the groups.

CSF FOLATE

Although the mean value in the depressed group was not significantly different when compared with the neurological control group, CSF folate was significantly lower in the high homocysteine depressed group $(t=2.46$, $\mathrm{p}<0.02$, table 2). CSF folate in CSF was significantly correlated with serum folate in both the whole depressed $(r=0.424, \mathrm{p}<0.05)$ and neurological control groups $(r=0.747$, $\mathrm{p}<0.001$ ), but did not correlate with red cell folate.

CSF S-ADENOSYLMETHIONINE

Concentration of SAM in CSF was not significantly different in the whole depressed group compared with the neurological control group. However, the high homocysteine depressed subgroup had a significantly lower mean CFS SAM concentrationin $(t=3.01, \mathrm{p}<0.01$, table 2). A significant negative correlation was found between CSF SAM and total plasma homocysteine in the total depressed group $(r=-0.399 ; \mathrm{n}=28 ; \mathrm{p}<0.05)$ but not in the neurological control group.

\section{CSF MONOAMINE METABOLITES}

Monoamine metabolites (5HIAA, HVA, and MHPG) in CSF were not significantly different in the whole depressed group compared with the neurological controls. However, the subgroup with high total plasma homocysteine had significantly lower mean CSF concentrations of the three metabolites: 5HIAA $(t=2.04$, $\mathrm{p}<0.05)$; HVA $(t=2.54, \mathrm{p}<0.02) ; \quad$ MHPG $(t=2.11, \mathrm{p}<0.04$, table 2$)$.

\section{Discussion}

We have confirmed that nearly one third of severely depressed inpatients have folate deficiency as indicated by a red cell folate concentration below $150 \mathrm{ug} / 1$. We have also shown that this is invariably accompanied by evidence of a functional deficiency state reflected by a raised total plasma homocysteine. Furthermore, a few other patients with borderline red cell folate concentrations or occasionally normal values also have raised plasma homocysteine, although in three of our patients this was due to 
vitamin B12 deficiency. Overall 52\% of patients had raised total plasma homocysteine. Red cell folate concentrations correlated significantly with plasma homocysteine. Those patients with raised homocysteine concentrations had the lowest red cell, serum and CSF folate values, which for each index were significantly different from the group of depressed patients with normal homocysteine concentrations. Homocysteine concentrations were unrelated to previous antidepressant medication, which is not known to influence homocysteine or folate concentrations.

The rise in total homocysteine in our patients indicates a failure of methylation of homocysteine to methionine due to a shortage of supply of methyl groups from methyl folate or, more rarely in depressed patients, lack of the vitamin B12 cofactor for this methylation reaction..$^{58}$ Methionine is in turn the immediate precursor of SAM, the methyl donor in many methylation reactions in the brain involving monoamines, neurotransmitters, proteins, nucleoproteins, and membrane phospholipids. ${ }^{51617}$ It is, therefore, of interest that the failure of one carbon metabolism in our depressed patients with folate deficiency associated with a high plasma homocysteine, was also accompanied by a significant fall in CSF SAM. Similar to folic acid, SAM has been reported to have effects on mood. ${ }^{5}{ }^{17}$

Our study also shows that depressed patients with high plasma homocysteine concentrations have significantly lower concentrations of the CSF monoamine metabolites 5HIAA, HVA, and MHPG suggesting an impairment in the metabolism of serotonin, dopamine, and noradrenaline, all of which have been implicated in the biology of affective disorders. ${ }^{9}$ Serotonergic, dopaminergic, and noradrenergic systems share many similar synthetic and degradative enzymes and a reduction in all three monoamine metabolites may indicate an effect at some common metabolic point. Several studies have already suggested a link between folate, SAM, and monoamine metabolism, probably through tetrahydrobiopterin $(\mathrm{BH} 4)$, the rate limiting pteridine cofactor required in the synthesis of monoamine neurotransmitters. ${ }^{10}$ Both experimental and clinical folate deficiency have been reported to be associated with impaired serotonin metabolism. ${ }^{18} 19$ We have previously reported a correlation between red cell folate, CSF BH4 and CSF 5HIAA and HVA in depressed patients. ${ }^{10}$ There is both experimental and clinical evidence that the administration of SAM is associated with an increased turnover of serotonin, dopamine, and noradrenaline.${ }^{17}$ Children with congenital deficiency of 5-10-methylenetetrahydrofolate had reduced concentrations of $\mathrm{CSF} \mathrm{BH} 4$ and CSF monoamine metabolites. ${ }^{20}$ In the rat cerebellum methyl folate modulated potassium evoked secretion of noradrenaline. ${ }^{21}$ Although there is evidence of a link between folate and biopterin metabolism that may lead to reduced monoamine metabolism in folate deficiency, the exact mechanism is not yet clear. An alternative mechanism has been proposed whereby methyltetrahydrofolate may play a neuromodulatory part at presynaptic sites by binding to glutamate receptors. ${ }^{22}$ The activation of presynaptic glutamate receptors have been shown to be involved in biogenic amine release. ${ }^{23}$

In summary, we have identified a biological subgroup of depressed patients with folate deficiency and impaired methylation and monoamine neurotransmitter metabolism. The subgroup is more easily detected with total plasma homocysteine concentrations, than with red cell folate, which in turn is more illuminating than serum folate. This subgroup is not detected by routine blood counts. The relatively high incidence of folate deficiency and raised homocysteine concentrations we have seen may reflect the severity and inpatient status of our depressed patients. In a study of outpatients with depression, raised plasma homocysteine was found in $20 \%{ }^{24}$ Our patients were not entered into a treatment study, but others have reported that depressed patients with low folate or raised homocysteine concentrations respond significantly less well to antidepressant medication. ${ }^{24}{ }^{25}$ We did note, however, that our patients with high homocysteine concentrations had slightly but significantly higher Hamilton scores. The importance of detecting these patients with low folate or raised homocysteine concentrations is further emphasised by the benefits of vitamin treatment in addition to psychotropic medication on the affective state which has been confirmed with placebo controlled trials of folic acid ${ }^{4}$ and methylfolate. ${ }^{3}$ Homocysteine test kits are now widely available in Europe and the USA at prices that vary between 15 and 60 pounds sterling or 25 to 95 dollars.

We are grateful to BioResearch, Milan, for financial support.

1 Crellin R, Bottiglieri T, Reynolds EH. Folates and psychiatric disorders. Clinical potential. Drugs 1993:45:623-36. 2 Carney MWP, Chary TKN, Laundy M, et al. Red cell folate concentrations in psychiatric patients. F Affect Disord 1990; 19:207-13.

3 Godfrey PSA, Toone BK, Carney MWP, et al. Enhancement of recovery from psychiatric illness by methyl folate. Lancet 1990;336:392-5.

4 Coppen A, Chaudry S, Swade C. Folic acid enhances lithium prophylaxis. Fournal of Affective Diseases 1986;10:9-13.

5 Reynolds EH, Carney MWP, Toone BK. Methylation and mood. Lancet 1984;ii:196-98.

6 Shorvon SD, Carney MWP, Chanarin I, et al. The neuropsychiatry of megablastic anaemia. BMF 1980;281: neuropsychia 1032 .

7 Stabler SP, Marcell PD, Podell ER, et al. Elevation of total homocysteine in serum of patients with cobalamin or folate deficiency detected by capillary gas chromatography-mass deficiency detected by capillary gas chromatog
spectrometry. $\mathcal{F}$ Clin Invest $1988 ; \mathbf{8 1}: 466-74$.

spectrometry. F Clin Invest 1988;81:466-74.
8 Lindenbaum J, Healton EB, Savage DG, et al. Neuropsychiatric disorders caused by cobalamin deficiency in the absence of anaemia or macrocytosis. $N$ Engl $\mathcal{F} \mathrm{Med}$ 1988;318:1720-8.

9 Trimble MR. Biological psychiatry. 2nd ed. New York: J Wiley, 1996.

10 Bottiglieri T, Hyland K, Laundy M, et al. Folate deficiency, biopterin and monoamine metabolism in depression. Psychol Med 1992;22:871-6.

11 Chanarin I. Laboratory haematology: an account of laboratory techniques. New York, NY: Churchill Livingstone, 1989.

12 Muir M, Chanarin I. Solid phase vitamin B12 assays using polycrylamide-bound R-binder. Br f Haematol 1983;53: polycrylam $423-35$.

13 Ubbink JB, Hayward Vermaak WJ, Bissbort S. Rapid highperformance liquid chromatographic assay for total homo-
cysteine levels in human serum. $\mathcal{f}$ Chromatogr 1991;565: 441-6. 
14 Giulidori P, Stramentinoli G. A radioenzymatic method for S-adenosylmethionine determination in biological fluids. S-adenosylmethionine determin
Anal Biochem 1984;137:217-20.

15 Bottiglieri T, Lim CK, Peters TJ. Isocratic analysis of MHPG, 5HIAA and HVA in cerebrospinal fluid by high performance liquid chromatography. $\mathcal{F}$ Chromatogr 1984; 311:354-60.

16 Baldessarini RJ. Neuropharmacology of S-adenosyl-Lmethionine. Am f Med 1987;83(suppl 5A):95-103.

17 Bottiglieri T, Hyland K, Reynolds EH. The clinical potential of ademetionine (S-adenosylmethionine) in neurological disorders. Drugs 1994;48:137-52.

18 Botez MI, Young SN, Bachevalier J, et al. Folate deficiency and decreased brain 5-hydroxytryptamine synthesis in man and rat. Nature $1979 ; 278: 182-3$

19 Botez MI, Young SN, Bachevalier J, et al. The effect of folic acid and vitamin B12 deficiency on hydroxyindoleacetic acid in human cerebrospinal fluid. Ann Neurol 1982;12: 479-84.
20 Hyland K, Smith I, Bottiglieri T, et al. Demyelination and decreased S-adenosyl methionine in 5,10methylenetatrahydrofolate reductase deficiency. Neurology 988;38:459-62.

21 Lucock MD, Green M, Levene MI. Methylfolate modulates potassium evoked neuro-secretion: evidence for a role at the pteridine cofactor level of tyrosine 3-hydroxylase. Neurochem Res 1995;20:727-36.

22 Ruck A, Kramer S, Metz J, et al. Methyltetrahydrofolate is a potent and selective agonist for kainic acid receptors. Nature 1980;287:852-3.

23 Wang J, Andrews H, Thukral V. Presynaptic receptors reguate noradrenaline release from isolated nerve terminals. $\mathcal{F}$ Neurochem 1992;58:204-11.

24 Fava M, Borus JS, Alpert JE, et al. Folate, B12 and homocysteine in major depressive disorder. Am f Psychiat 1997;154:426-8.

25 Reynolds EH, Preece JM, Bailey J, Coppen A. Folate deficiency in depressive illness. Br f Psyciat 1970;117:287-92. 